\title{
CAEP/ACMU 2016 Research Abstract Awards
}

First place, Plenary Presentation, Grant Innes Research Paper and Presentation Award Andrew McRae

PL001 Derivation of a 2-hour high-sensitivity troponin $\mathrm{T}$ algorithm for rapid rule-out of acute myocardial infarction in emergency department chest pain patients

\section{Second place, Plenary Presentation}

Samina Ali

PL002 A randomized controlled trial on oral analgesic utilization for children presenting with a musculoskeletal trauma in the emergency department

\section{Third place, Plenary Presentation}

Alexander Leung

PL003 Impact of process improvements on measures of emergency department efficiency

Fourth place, Plenary Presentation, Top Resident Abstract Award

Sameer Masood

PL004 A population-based analysis of outcomes in patients with a primary diagnosis of hypertension in the emergency department, using linked datasets
Top New Investigator Award

Catherine Varner

LO084 Text messaging research participants as a follow-up strategy to decrease emergency department study attrition

\section{Top Pediatric Abstract Award}

Samina Ali

LO049 Ibuprofen or oxycodone? An observational cohort study of post-emergency department discharge management of children's fracture pain

\section{Top Medical Student Project Award}

Nicole Beckett

LO040 A Do combined electrocardiogram rhythm and point of care ultrasound findings predict outcome during cardiac arrest? The second Sonography in Hypotension and Cardiac Arrest in the Emergency Department (SHOC-ED 2) Study

\section{Top Education Innovation Abstract Award} Fareen Zaver

LO102 ALiEM AIR-Pro Series: Identifying quality content from blogs and podcasts for the senior emergency medicine resident

\section{CAEP Resident Research Abstract Awards}

Cristian Toarta

LO004 Short-term risk of arrhythmias among syncope patients presenting with atrial fibrillation/ flutter to Canadian emergency departments
Neil Dattani

LO005 Association between emergency department chest pain volume and outcomes among patients presenting with chest pain 
Audrey-Anne Brousseau

LO034 Does head injury matter? Comparison of functional outcomes in elderly who have sustained a minor trauma with or without head injury: a prospective multicenter cohort study

Alexis Cournoyer

LO041 Predicting the return of spontaneous circulation using near-infrared spectroscopy monitoring: a systematic review and metaanalysis

\section{Kyle McGivery}

LO074 Point of care ultrasound for lung B-lines in the early diagnosis of acute decompensated heart failure in the emergency department: a systematic review.

\section{Robert Ohle}

LO075 Clinical exam for acute aortic dissection: a systematic review and meta-analysis

Nicholas Costain

LO099 Colchicine in acute and recurrent pericarditis: a meta-analysis

\section{CAEP/ACMU 2016 Grant Awards}

\section{EMAF Grant Awardees}

Simon Berthelot

Feasibility assessment of two activity-based costing methods for value-based analysis in the emergency department

Jocelyn Gravel

Should we use oral Valacyclovir in acute herpetic gingivostomatits in children? A randomized controlled trial

\section{Junior Investigator Awardees}

Dennis Cho

Optimizing practice for learning emergency department transthoracic echocardiography using an ultrasound simulator

Véronique Dion

Définition des valeurs normales de la veine cave inférieure en pédiatrie à l'échographie au département d'urgence
Jean-Simon Letourneau

Acceptabilité et adaptation pour l'urgence d'un outil d'aide à la prise de décision partagée dans le recours à l'antibiothérapie pour traiter les infections respiratoires aigues

Laurie Robichaud

The use of point-of-care ultrasound in the diagnosis of acute infectious mononucleosis in the emergency department

\section{Brent Thoma}

The METR:IQ (Medical Education and Translational Resources: Indicators of Quality) Study: Assessing the quality of novel educational resources 